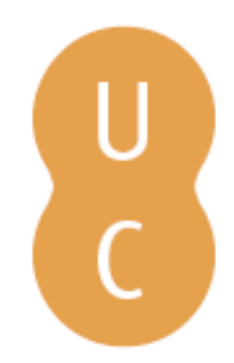

\title{
nommalina
}

\section{A Câmara Portuguesa de Comércio e Indústria do Rio de Janeiro: uma associação empresarial da Primeira República}

\author{
Autor(es): $\quad$ Mourão, Alda \\ Publicado por: Imprensa da Universidade de Coimbra \\ URL \\ persistente: URI:http://hdl.handle.net/10316.2/35883 \\ DOI: $\quad$ DOI:http://dx.doi.org/10.14195/978-989-26-0862-4_16 \\ Accessed : $\quad$ 26-Apr-2023 09:41:22
}

A navegação consulta e descarregamento dos títulos inseridos nas Bibliotecas Digitais UC Digitalis, UC Pombalina e UC Impactum, pressupõem a aceitação plena e sem reservas dos Termos e Condições de Uso destas Bibliotecas Digitais, disponíveis em https://digitalis.uc.pt/pt-pt/termos.

Conforme exposto nos referidos Termos e Condições de Uso, o descarregamento de títulos de acesso restrito requer uma licença válida de autorização devendo o utilizador aceder ao(s) documento(s) a partir de um endereço de IP da instituição detentora da supramencionada licença.

Ao utilizador é apenas permitido o descarregamento para uso pessoal, pelo que o emprego do(s) título(s) descarregado(s) para outro fim, designadamente comercial, carece de autorização do respetivo autor ou editor da obra.

Na medida em que todas as obras da UC Digitalis se encontram protegidas pelo Código do Direito de Autor e Direitos Conexos e demais legislação aplicável, toda a cópia, parcial ou total, deste documento, nos casos em que é legalmente admitida, deverá conter ou fazer-se acompanhar por este aviso.

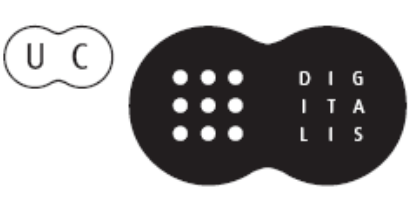




\title{
A EXPERIÊNCIA DA PRIMEIRA REPÚBLICA NO BRASIL E EM PORTUGAL
}

\author{
ALDA MOURÃO \\ ANGELA DE CASTRO GOMES
}

COORDENAÇÃO 


\section{A Câmara Portuguesa de Comércio e Indústria do Rio de Janeiro: uma associação empresarial da Primeira República}

Alda Mourão

NOS PRIMEIROS ANOS DO SÉCULO XX VERIFICAVA-SE UMA CONJUNTURA desfavorável para a comunidade portuguesa no Brasil: para além da antiga relação colónia/colonizador, antes de 1910 a República brasileira não tinha afinidade com o regime monárquico português. Entre os republicanos portugueses e os brasileiros também não se verificava uma similitude ideológica plena, o que ficou expresso por Sampaio Bruno e por João Chagas, aquando do seu exílio no Brasil, após a fracassada revolta de 31 de Janeiro de 1891, em que tinham participado. O primeiro deles criticara o republicanismo brasileiro que tornara o "positivismo um catolicismo sem Deus", como assinala Eulália Lobo. ${ }^{1}$

Havia mais razóes para que os portugueses não tivessem uma imagem muito favorável, perante os brasileiros, nos inícios de Novecentos. O passado comum legara outra situação, alvo de descontentamento: no Rio de Janeiro, por exemplo, os portugueses eram apontados como senhores do monopólio de algumas das áreas de comércio entre os conterrâneos, como o da venda de bens alimentares, de bebidas ("secos e molhados"), de tecidos, bem como através das padarias, restaurantes, casas de crédito. Usando dados da Junta do Comércio, Wagner Chagas de Menezes (1998:79-81), num estudo sobre o pequeno comércio no centro do Rio de Janeiro, concluiu que os portugueses eram aí proprietários de 40 a $46 \%$ dos pequenos estabelecimentos comerciais, entre

\footnotetext{
${ }^{1}$ A autora traça o quadro destas divergências, acompanhando o percurso do pai, António Dias Leite, também ele um exilado no Brasil, à época. In: Lobo et al. (2005:29-30).
} 
1889 e 1903 . Acresce, a tudo isto, o facto de se tratar de uma comunidade imigrante, cujo país de origem se apresentava como o sexto, entre os países exportadores para o Brasil, em 1912, "e eram os principais supridores de géneros alimentícios básicos, tais como feijão, bacalhau, azeites, vinhos, vegetais e milho, bem como de tecidos da manufactura portuguesa e matéria-prima" (Lobo, 2001:33). O controlo do comércio, por parte dos portugueses, era enorme. ${ }^{2} \mathrm{O}$ que fundamentou alguma "lusofobia", por se tratar de um grupo coeso, que se abria aos artigos de importação portuguesa e à mão de obra dos "patrícios" que chegavam, remetendo as poupanças para a terra natal, por pretender regressar a ela, quando enriquecido. Representava, também, um mercado consumidor de bens e serviços significativo. $\mathrm{Na}$ ótica dos comerciantes portugueses a situação parecia não ser exatamente esta, em 1915: pela palavra do sócio da Câmara Portuguesa de Comércio e Indústria do Rio de Janeiro, Adriano Castro Guidão, "há muitos portugueses que não compram artigos do seu país porque desconhecem o grau de adeantamento que certas industrias teem atingido em Portugal". ${ }^{3}$ Razão que justificava o apoio que pedia para a realização de uma exposição permanente de produtos portugueses, a ter lugar em espaço da Embaixada lusa.

Acresce que o Brasil se encontrava, então, num processo de desenvolvimento urbano, principalmente evidente nas cidades costeiras, cujos portos permitiam o escoamento dos seus produtos, com destaque para o café, mas também das cidades situadas entre estes e os centros produtores. Era o tempo das grandes obras que criavam as infraestruturas para um Brasil que queria aproximar-se do mundo civilizado, sobre a herança do atraso em que a colonizaçáo portuguesa o deixara.

Numa sociedade que carregava o estigma de capital de antiga colónia, não deixariam de existir marcas de repulsa ao passado. O Rio de Janeiro ansiava pela modernização, através dos modelos que chegavam de uma Europa, cujo desenvolvimento não incluía Portugal. Os símbolos do progresso e da civilização eram a Inglaterra e a França.

\footnotetext{
${ }^{2}$ António Torres, jornalista, citado por Eulália Lobo (2001:35), aponta 85\% como o espaço ocupado pelo comércio português no Distrito Federal do Rio de Janeiro, em 1923.

${ }^{3}$ Câmara Portuguesa de Comércio e Indústria do Rio de Janeiro (CPCI). Ata do Conselho Diretor, 6 Set. 1915.
} 


\section{Práticas de associativismo}

As primeiras décadas do século XIX conheceram o crescendo do associativismo. Em Portugal, como nos países cujo modelo económico evoluíra, à semelhança do registado na Europa Ocidental, já antes se sentira a necessidade em criar estruturas que congregassem diferentes sectores da vida nacional. Se o final do século XVIII assistira ao despontar deste movimento, que se revelou no âmbito científico, a revolução de 1820 criou as condiçóes para que se acentuassem os debates, decorrentes de uma nova mentalidade. Esta se fora formando, internamente, através da Universidade de Coimbra e daqueles que regressavam ao país, dando a conhecer realidades associativas concretizadas na Europa mais evoluída. ${ }^{4}$

Como sector económico à procura das vantagens criadas pela conjuntura liberal, o comércio iniciou as primeiras experiências associativas. Sancionava-se a ideia de que a classe comercial era a que melhor compreendia o princípio do associativismo (Goodolphim, 1879). As razóes, vamos buscá-las ao facto de ser numerosa, de integrar um sector em constante (re)organização, de sofrer, de forma mais imediata, o impacto das flutuaçóes dos mercados internacionais. Assim, logo em 1834, Porto e Lisboa assistiram à criação das suas Associaçóes Comerciais. ${ }^{5}$ Nos anos seguintes, será a vez das cidades insulares de Ponta Delgada e Funchal. Por seu lado, o sector industrial tentava reagir à perda que gravemente o atingira, com a abolição das organizaçóes de tipo corporativo. $\mathrm{O}$ quadro político que se seguiu à Revolução de Setembro de 1836 foi sensível a esta situação, pela política industrialista que defendia, e que a extinção da Casa dos Vinte e Quatro possibilitava. ${ }^{6}$ Poucos anos mais tarde, em 1849, os industriais portuenses reagem e fundam a sua Associação de classe (Brito, 1996:75-76).

\footnotetext{
${ }^{4}$ Sobre a nova intelligentsia que interveio no desenvolvimento associativo, ver Matos (1996).

${ }^{5}$ Relativamente à Associaçáo Comercial do Porto, os seus primeiros 10 anos de vida foram analisados por Bonifácio (1986:331-367). Ainda entre as primeiras experiências, contou-se com a criaçáo da Associaçáo Artista e Industrial da Cidade do Porto, em 1838. Cf. Alves (1996). No que diz respeito à criação da Associação Comercial de Lisboa, em 1834, ela resultou da açáo de um grupo de comerciantes que constituíram a Associação Mercantil Lisbonense. Em Fevereiro de 1855, esta passará a denominar-se Associação Comercial de Lisboa.

${ }^{6}$ José M. Amado Mendes (1993) defende esta mesma relação, entre um desenvolvimento, que se preparava, e uma estrutura secular, que expirava.
} 
No Rio de Janeiro, a experiência do associativismo desenvolveu um modelo muito semelhante ao percorrido em Portugal, como demonstra Théo Piñero num estudo sobre as entidades empresariais, no período do Império (Piñero, 2009). No caso do Rio de Janeiro, a Associação Comercial foi fundada em 1867, como herdeira de uma estrutura anterior, a Sociedade dos Assinantes da Praça (1834) que, por sua vez, evoluíra do Corpo do Comércio.

A ideia de "câmara de comércio", criada nos finais do século XIX pela legislação portuguesa, integrada no Código Civil de 1870 e regulamentada por Decreto de 9 de Maio de 1891, surgiu na sequência óbvia de modelos internacionais, com incubação no interior das Associaçóes Comerciais de maior dimensão, como a de Lisboa ou a do Porto.

Do outro lado do Atlântico, os empresários de origem portuguesa organizaram-se, no sentido de criarem uma estrutura semelhante, num movimento que se iniciou no Rio de Janeiro. Também aqui foi notório o protagonismo assumido pelos comerciantes. Como a generalidade das associaçóes que congregam interesses profissionais, a então criada Câmara Portuguesa de Comércio e Indústria do Rio de Janeiro (CPCI) representou também uma "comunidade de interesses" (Durkheim, 1989:19), patente nos seus Estatutos e na sua prática filantrópica e social. Ela combinava estes interesses com a partilha da origem territorial dos seus associados, com a distância que os separava dos corredores de decisão dos governantes portugueses e com a necessidade de dialogar com os órgãos do poder brasileiro.

\section{A fundação da Câmara Portuguesa de Comércio e Indústria}

No dia 16 de Setembro de 1911 foi publicado o Decreto que criava a CPCI, como resposta dada pelo governo português ao movimento dirigido por um grupo de empresários portugueses que se haviam reunido à volta da ideia de fundar uma estrutura que defendesse os seus interesses, no Rio de Janeiro. ${ }^{7}$ O poder político criara, mas na realidade ainda não existia tal estrutura. O que significava que os esforços se redobraram nos meses seguintes, no sentido de

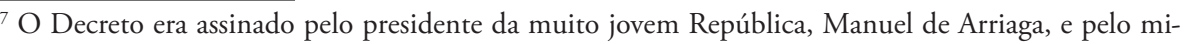
nistro do Fomento, Sidónio Pais. Aprovava, em simultâneo, os Estatutos da Câmara, que constavam em anexo ao texto legal.
} 
concretizar o que estava consignado na lei. Verificou-se uma mobilização de vontades, organizadas em Comissão, para conseguir uma lista de negociantes que, em Outubro seguinte, foi entregue na Repartiçáo do Comércio da, entáo, capital do Brasil. ${ }^{8}$ Entre as firmas que se apresentaram a assinar essa manifestação de intençóes, constavam nomes de algumas já bem instaladas na praça comercial carioca. ${ }^{9}$ Em Dezembro, com o estabelecer de contactos em Lisboa, junto de algumas personalidades influentes no novo regime, o movimento atuava do lado de cá do Atlântico. Pretendia-se sensibilizar os dirigentes políticos da importância desta iniciativa, em face dos interesses económicos em causa e da dimensão da colónia portuguesa no Rio de Janeiro. ${ }^{10}$

O grupo contou com o grande apoio do Consulado Geral de Portugal que, claramente, mostrava ser a ligação entre o governo português, recém-eleito, e os interesses económicos da comunidade imigrante. Em Janeiro de 1912, reuniu a Comissão Organizadora da Câmara Portuguesa de Comércio e Indústria do Rio de Janeiro com o Cônsul Geral em exercício, Filipe de Sousa Belford. ${ }^{11}$ O principal tema em agenda dizia respeito ao financiamento da Câmara. Partia-se do cálculo de um orçamento anual, que incluía o aluguer de instalações, pagamento a funcionários, material de expediente e publicação trimestral (Boletim), que viria a orçar $45.800 \$ 000$. Esta verba era aliviada em 12 contos de reis, provenientes da anuidade dos 200 sócios previstos. ${ }^{12}$ No final, restava o valor que era pedido ao Estado português para a fase de instalação: $33.800 \$ 000$.

Nos meses seguintes, as diligências desenvolvem-se, no sentido de permitir que efetivamente entrasse em atividade a primeira das Câmaras Portuguesas de Comércio e Indústria, não só no Brasil, como no resto do mundo. ${ }^{13}$ Era

\footnotetext{
${ }^{8}$ Em 17 de Outubro de 1911, tinha sido apresentada, na Repartição do Comércio, do Ministério do Fomento, uma lista de "Firmas signatárias para requerer a constituição de uma Câmara de Comércio no Rio de Janeiro”, onde constavam 45 assinaturas (CPCI. Documentação Avulsa).

${ }^{9}$ A título de exemplo, pela importância que ainda hoje mantém, registamos Lebrão \& C C prietária da famosa Pastelaria Colombo.

${ }^{10}$ Estes encontros, que juntaram Eusébio Leão e Serafim Clare, ocorreram no início do mês de Dezembro, de 1911, aquando da estadia deste último em Portugal, apresentando-se como representante do movimento. Ata da reunião da Comissão Organizadora da Câmara Portuguesa de Comércio e Indústria do Rio de Janeiro, 17 Jan. 1912 (CPCI. Documentação Avulsa).

${ }^{11}$ Ibid.

${ }^{12}$ Tomando em consideraçáo as folhas de assinatura, que correram aquando da sessão de instalaçáo da Câmara Portuguesa, em 10 de Agosto, o número de potenciais sócios era de 115. Pouco depois da fundação, já contavam com uma lista de 286 sócios (CPCI. Documentação Avulsa).

${ }^{13}$ Cf. Paulo (2004:369-390). Em Novembro de 1912, iniciava-se, também, a criação desta mesma
} 
evidente que para a jovem República Portuguesa estas associaçóes eram estruturas prestigiantes para a sua própria afirmação no estrangeiro. $\mathrm{O}$ significado do momento da sua criação ganha maior relevo por antecipar as suas congéneres estrangeiras, na praça do Rio de Janeiro.

Finalmente, no dia 10 de Agosto de 1912 teve lugar a sessão solene que marcou o início das atividades da Câmara Portuguesa de Comércio e Indústria (CPCI) do Rio de Janeiro, no salão Nobre da Associação Comercial, como noticiou o periódico carioca Jornal do Commercio, desse mesmo dia, tendo-lhe dedicado grande parte da primeira página. Foi presidida por Bernardino Machado, futuro presidente da República, como enviado extraordinário e ministro plenipotenciário no Brasil.

Foi inquestionável a grande intervenção do governo de Lisboa na vida da nova associação, logo evidenciada pela longa estadia, no Rio de Janeiro, de Bernardino Machado, a acompanhar o lançamento da CPCI, tendo sido o dinamizador da primeira sessão do Conselho Diretor, que teve lugar no dia 26 de Outubro. ${ }^{14}$ Coube, ao estadista, apresentar o estudo da linha de navegaçáo a estabelecer entre Portugal e o Brasil. Este era, aliás, um dos grandes problemas sentido por toda a comunidade portuguesa, e que se manterá pela falta de resposta do lado português e pela oferta desenvolvida por alguns países europeus. ${ }^{15}$

Esta relação com o poder era notória, através do protagonismo assumido pelo representante do Estado português, o embaixador ou, na sua ausência, o cônsul de Portugal no Rio de Janeiro. As reunióes do Conselho Diretor eram

\footnotetext{
estrutura associativa em Sáo Paulo; replicou-se o modelo dinamizado por um grupo de cidadáos portugueses "residindo e laborando nesta Capital Estadual" para fundar a Câmara Portuguesa de Comércio de São Paulo. Em finais de 1913, foi eleito o seu primeiro presidente e, em Fevereiro do ano seguinte, os estatutos da Câmara de São Paulo foram aprovados pelo governo português. Em Paris, seria criada em 1918 .

${ }^{14}$ Sobre esta presença, o Relatório acrescenta: "Sua Excelência não se limitou apenas a instalar a nossa Câmara. Amparou-a por assim dizer nos seus primeiros passos vacilantes. Espontaneamente se instituiu seu mentor, guiando-a nos menores atos. Deu-lhe vitalidade e elevou-a no conceito das sociedades congéneres da metrópole". In: RELATÓRIO do Conselho Diretor apresentado à Assembleia-geral em sessão de 27 de Janeiro de 1916. Gerência de 10 de Agosto de 1912 a 31 de Dezembro de 1915. p. 15. ${ }^{15}$ Em 1920 é dada a notícia, no Relatório Anual, de que "aportou ao Rio de Janeiro o primeiro paquete que veio inaugurar a tâo desejada carreira de navegação de Portugal para a América do Sul”. Mas o futuro não conduzirá à amplitude necessária da iniciativa, náo evoluindo como era expectável, no quadro conjuntural do pós-guerra. E assim se irá manter nas décadas seguintes, colhendo outros argumentos, que mascaravam a incapacidade para responder às necessidades da colónia portuguesa.
} 
por si presididas, como previam os Estatutos. Dos objetivos que pautavam a vida da Câmara, e que passavam por: "defender e promover as relaçôes comerciais e industriais entre Portugal e o Brasil; representar e defender os interesses das classes que a compóem", era definido que ela estava "em relaçóes com o Governo Português, diretamente com todos os ministérios e, indiretamente, por meio das autoridades diplomáticas e consulares".

Os primeiros anos de vida da Câmara Portuguesa de Comércio e Indústria do Rio de Janeiro ficaram registados no Relatório do Conselho Diretor, na gerência de 1912 a $1915,{ }^{16}$ a que se associam as publicaçóes oficiais, as atas das reuniōes da direção, as fichas de matrícula de sócios. ${ }^{17}$

A intervenção da Câmara acompanhou de perto os interesses que se iam desenhando na vida dos associados, em particular, e da colónia portuguesa estabelecida no Rio de Janeiro, em geral.

O lado filantrópico também esteve presente, principalmente em benefício dos "patrícios" indigentes, impossibilitados de regressar a Portugal. O ano de 1914 foi particularmente sensível a esta situação. A véspera da Primeira Grande Guerra precipitou a entrada "desacautelada", no Brasil, de imigrantes portugueses, que erravam pela cidade do Rio de Janeiro à procura da ocupaçáo que náo encontravam. O Consulado manifestou incapacidade financeira para proceder à sua "repatriaçáo". A CPCI decidiu abrir uma subscrição pública que rendeu cerca de 8 contos de reis. ${ }^{18}$

Ao lado da representação diplomática do governo português, a CPCI fazia-se representar sempre, através dos seus dirigentes, aquando da chegada de uma qualquer personalidade de vulto, ao Rio de Janeiro: cônsules, embaixadores, ministros, chefes de Estado. Assumia estes atos públicos como se de um representante oficial, de alto nível, se tratasse.

A instalação da Câmara, como um dos símbolos de estatuto e de poder ambicionados por qualquer organização, foi um dos problemas iniciais com

\footnotetext{
${ }^{16}$ RELATÓRIO do Conselho Diretor apresentado à Assembleia-geral em sessão de 27 de Janeiro de 1916. Gerência de 10 de Agosto de 1912 a 31 de Dezembro de 1915. CPCIRJ, Rio de Janeiro, 1916. ${ }^{17}$ Como publicação periódica, temos o Boletim, mensal, cujo primeiro número foi publicado em Janeiro de 1913. Era de distribuição gratuita entre os sócios. Por seu lado, também as atas das reuniōes de direção retrataram, sempre sumariamente, as diferentes fases da vida da CPCI. Os Relatórios do Conselho Diretor constituem outro fundo de informação, para além da documentaçáa avulsa, disponibilizada pela direção da CPCI (RJ).

${ }^{18}$ Cf. RELATÓRIO do Conselho Diretor..., p. 42-44.
} 
que os dirigentes se confrontaram. A maior das ambiçóes será, sem dúvida, possuir sede própria. Hoje a CPCI ocupa instalaçóes que lhe conferem a dignidade de estrutura representativa dos empresários portugueses, no edifício da Federação das Indústrias do Estado do Rio de Janeiro (Firjan), bem no centro económico da cidade, desde 2005.

Para trás, ficou um elenco de espaços, nem sempre compatíveis com a respeitabilidade desejada. Em 1955, através do manuscrito do discurso a proferir no dia de aniversário da associação, certamente da responsabilidade de um seu dirigente, ${ }^{19}$ lembravam-se os primeiros tempos:

A Câmara foi instalada numa sala, aliás sem conforto algum, da Associação Comercial do Rio de Janeiro. Posteriormente se mudou para as salas 21 e 22 do $2^{\circ}$ andar do Jornal do Comércio e a seguir para um óptimo saláo localizado no $3^{\circ}$ andar do mesmo edifício, onde ficou até que, em 8 de Setembro de 1923, fomos, juntamente com o Consulado Geral de Portugal, parar ao 1o andar do Liceu de Artes e Ofícios, com frente para a Avenida Rio Branco. Em 26 de Janeiro de 1931, mudámos para o [Real] Gabinete Português de Leitura, de onde viemos para esta sede, em 15 de Fevereiro de 1949.

Estas novas instalaçóes, onde se encontrava em 1955, situavam-se no $14^{\circ}$ andar do no 463, da avenida Presidente Vargas. ${ }^{20}$

Mas regressando a Outubro de 1920, em face da aspiração já então sentida pela CPCI de "construir um edifício onde condignamente se instale", o pintor açoriano Domingos Xavier Rebello ofereceu um quadro a óleo da sua autoria, para que pudesse servir de angariação de algum capital. ${ }^{21} \mathrm{O}$ quadro, intitulado "Freguesia de Água de Pau", foi objeto de uma tômbola, para a qual se fizeram 500 bilhetes, com o valor de $20 \$ 000$ cada. ${ }^{22}$ Esta iniciativa foi rapidamente concretizada, com a venda, que se iniciou no dia 30 desse mês.

\footnotetext{
${ }^{19}$ Trata-se de um texto dactilografado, corrigido à mão, que faz um historial da CPCI, no dia dos seus 43 anos. Não foi possível identificar o autor, por não se encontrar um texto assinado ou publicado no Boletim (CPCI. Documentação Avulsa).

${ }^{20}$ Cf. Relatório da Diretoria, 1949-1950. Por este documento ficamos a saber um pouco mais: mudaram, depois "dos pedidos que, insistentemente, lhe eram feitos para a desocupaçáo do saláo que o Real Gabinete precisava”.

${ }^{21}$ Arquivo da CPCI. "Correspondência Avulsa". Carta de Domingos Xavier Rebello para a direção, 20 Out. 1920.

${ }^{22}$ Id., carta da direção para o pintor, 30 Nov. 1920.
} 
Planeou-se arrecadar, pelo menos, a quantia de $9.000 \$ 000$ reis. Mas a diligência não correu como era esperado, com o incumprimento por parte de alguns compradores, bem com a devolução de muitos dos bilhetes distribuídos. Foi o caso da firma Pereira, Almeida \& Cia, que devolvia os quatro bilhetes recebidos, alegando a ausência do sócio Álvaro Pereira de Magalhães Coutinho; ${ }^{23}$ ou da Pedrosa Monteiro \& Cia, que devolvia os dois bilhetes, sem qualquer justificação. ${ }^{24} \mathrm{Da}$ mesma forma procederam as firmas S.A. Monitor Mercantil, ao devolver dois dos quatro bilhetes recebidos; a Lusitânia Store, que ficou só com um de dois enviados; o mesmo se verificando com a firma de Vitorino Moreira, a Fábrica de Móveis de Moreira Mesquita, a firma Heitor Ribeiro \& Cia. A Casa Merino e Cia não aceitou qualquer bilhete, bem com a Soares $\&$ Resende, Gomes de Castro \& Cia. Alfredo Gestal adiantou um pouco mais, ao fazer a devolução "por motivos estranhos à minha vontade". ${ }^{25} \mathrm{O}$ sócio da firma Ferreira, Baltazar \& Cia tornou-nos curiosos quando escreveu, no cartáo que acompanhava a devolução: "Não podendo nós, por motivo que aqui se torna inútil enumerar, aceitar o bilhete". ${ }^{26}$ Henrique Santos, sócio da Farmácia e Laboratório Dermol, sentia-se forçado a tomar a decisão de não colaborar na iniciativa "para uma obra tão patriótica" ${ }^{27} \mathrm{O}$ guarda-livros da firma Silva Assumpção \& Cia declara mesmo que procede à devolução dos bilhetes, "em virtude do chefe Sr. Silva Assumpção não me autorizar a fazer o pagamento" ${ }^{28}$

As manifestaçôes de clara adesão à iniciativa, apesar de mais raras, também se fizeram sentir. Bastos Dias, sócio de uma empresa de Importação, ao proceder ao pagamento dos seus bilhetes, adiantava que, caso ganhasse o quadro a óleo, "desde já o oferece para o Salão Nobre da Câmara". ${ }^{29}$

Não temos dúvida de que se fazia sentir um mal-estar entre a Direção e uma parte dos seus associados. Seria o sócio Domingos José de Araújo, com armazém de vinhos e comestíveis, instalado na rua da Alfândega, que revelaria

\footnotetext{
${ }^{23}$ Id., ofício da firma citada, recebido em 19 Nov. 1920.

${ }^{24}$ É de notar que, entre esta correspondência, também se encontram sócios que remetem o valor dos bilhetes adquiridos: A. Cunha \& Silva, Lda., Sotto Mayor \& Cia; Simôes Macedo \& Cia; N. Guimarăes \& Cia, a título de exemplo.

${ }^{25}$ CPCI. Correspondência Avulsa. Carta de Alfredo Gestal, 20 Nov. 1920.

${ }^{26}$ Id., cartão de 11 Nov. 1920.

${ }^{27}$ Id., carta de 10 Nov. 1920.

${ }^{28}$ Id., carta de 11 Nov. 1920.

${ }^{29}$ Id., carta de 8 Nov. 1920.
} 
o motivo que estava a perturbar a vida da CPCI: em carta datada de 13 de Novembro, faz acompanhar os bilhetes devolvidos à Direção escrevendo: "facilmente V.Ex.as compreenderão que só podem concorrer para a requisição de sede própria aqueles que também têm sede própria”. A diferenciação entre estatutos económicos dos associados da CPCI veio ao de cima neste momento. Considerando o baixo número de bilhetes distribuídos e o grande objetivo que se pretendia alcançar, a direção confrontou-se com uma crise, instalada entre os seus associados. Por certo selecionou aqueles a quem pediu que reconsiderassem o seu gesto. Nesta sequência, dirigiu-se a alguns deles, como aconteceu com Albino Bordalo Garcia. Na carta enviada, como resposta a mais uma devolução de um bilhete, era manifestado o pesar sentido "por se tratar de um compatriota de destaque na colónia que sempre tem patrocinado todas as obras para o engrandecimento da açáo dos portugueses no Brasil”. A acompanhar a missiva enviava-se um novo bilhete com a nota final de "esperando esta Diretoria dever-lhe do seu amor cívico a fineza de o aceitar" ${ }^{30}$ Usando da mesma argumentação, foi enviado outro bilhete ao sócio Joaquim Dias Garcia. Estranhamente, estes ofícios foram escritos no mesmo dia em que se dava por terminada a iniciativa. Isto é, saldaram-se as contas, e a CPCI entendeu entregar ao autor cerca de $30 \%$ do valor, atendendo às despesas com os materiais e o transporte, isto é, $2.700 \$ 000$ reis.

Não foi uma iniciativa bem-sucedida. E a aspiração por uma sede com instalaçốes próprias manteve-se.

\section{Os primeiros anos de vida}

\subsection{A vida associativa}

Através das atas das reunióes, dos relatórios e da correspondência trocada, é possível construir o lado mais público da vida da Câmara Portuguesa de Comércio e Indústria do Rio de Janeiro. O privado da evolução das relaçóes entre os sócios e, principalmente, entre estes e os grupos diretores ficou no vazio criado intencionalmente na informação.

\footnotetext{
${ }^{30}$ Id., ofício da directoria da CPCI, 20 Nov. 1920.
} 
A primeira reuniáo de direção decorreu às 15 horas do dia 28 de Agosto de 1912, sob a presidência de José Pereira Sousa, num gabinete do Consulado de Portugal, no Rio de Janeiro, cedido para o efeito. Os assuntos tratados prenderam-se exclusivamente com instalação e criação identitária, através dos símbolos já assumidos. ${ }^{31}$

Os trabalhos prosseguiram com a resolução de toda uma série de necessidades inerentes à fundação de uma instituição, com estatuto já reconhecido pelo país de origem, bem como pelo país de acolhimento: contrataçáo de pessoal, compra de mobiliário, colocação de placa identificadora no edifício, aquisição de telefone, aluguer de caixa postal, impressão de estacionário que transmitisse a identidade da CPCI.

Foi pedida a intervenção da associação para obstar à violação das mercadorias chegadas ao porto da cidade, principalmente quando em causa estavam os vinhos portugueses. Ligada a este produto, a capacidade negociadora da CPCI foi posta à prova quando se concretizou a aplicação da lei que previa o aumento do imposto de consumo para vinhos estrangeiros, logo em Outubro de 1912. Que ganhou, colocando os vinhos portugueses entre os beneficiários da suspensão da medida.

Seguem-se outros desafios, ao longo dos primeiros anos de vida. Entre os mais importantes destacam-se as ligações marítimas entre as duas capitais, que se tornaram uma reivindicação sempre presente, até aos anos 1960. Também a uniformização do vasilhame do azeite e do vinho exportado para o Brasil, como forma de credibilizar estes produtos, concentrou os esforços de importadores e exportadores. ${ }^{32}$ Outra causa foi a da criaçáo de um porto franco, em Lisboa, que permitisse a redução de taxas alfandegárias para animar o comércio luso-brasileiro.

A CPCI vai pugnar para que se instale um novo sentimento de troca recíproca de bens, entre Lisboa e o Rio de Janeiro. Disso mesmo fazia jus a sua publicação institucional, $O$ Boletim, que, ao longo dos anos, registava listas de produtos trocados através de ambos os portos. Vinhos, de toda a qualidade, conservas de peixe, azeite e algumas leguminosas secas, como o feijão e as favas, contavam-se entre os mais significativos que tinham gosto português, enquan-

\footnotetext{
${ }^{31}$ LIVRO de Atas da Câmara Portuguesa de Comércio e Indústria do Rio de Janeiro. Ata número1, 28 Ago. 1912.

${ }^{32}$ Esta causa esteve muito presente em diversos números do Boletim, ao longo de 1915.
} 
to o algodão e os couros secos brasileiros dominavam um elenco menos diversificado de produtos exportados. ${ }^{33}$

Seguir-se-á a organizaçáo de exposiçóes de produtos portugueses, a organização e a participação em eventos culturais, quer brasileiros, quer portugueses, a angariaçáo de fundos para a construçáo de monumentos considerados identitários da nossa cultura, como Luís de Camōes e Eça de Queirós. ${ }^{34}$

No final do ano de 1916, a direção orgulhava-se, no seu Relatório, de ter congregado a colónia "dividida até então por lutas partidárias, e levado a efeito, após afronta da omnipotente Germânia”. O Brasil importara a questáo que dividia a sociedade portuguesa, entre os que defendiam e os que rejeitavam a política externa republicana. Deste êxito decorrera a criação da Comissão Pró Pátria, que se instalou na sede da CPCI, que se veio a tornar a Assistência aos Órfãos de Guerra e, mais tarde, financiou a criação do Hospital da Colónia Portuguesa, em Coimbra, hoje denominado Hospital dos Covôes.

Foi rápida esta vivência em paz: no biénio de 1919-20 verificou-se uma viragem mais profunda na vida da CPCI, até então marcada por um equilíbrio nas relaçóes entre sócios. A mudança foi evidente com o episódio gerado pela campanha para a construção da sede, registado anteriormente. A partir deste período, sucederam-se as renúncias a cargos de direçáo, sob o pretexto de ausências do Rio de Janeiro. Situação que se estendeu até 1924. Em causa estava a crise vivida em Portugal, como confirma o Relatório desse mandato.

\subsection{O quadro social}

Os Estatutos da CPCI, do Rio de Janeiro, no seu Capítulo 8, relativo aos fundos, indicavam como principal fonte de receita as quotas dos sócios. A elas juntavam-se os donativos, os rendimentos dos seus capitais, o produto das vendas do Boletim e, finalmente, quaisquer rendas ou benefícios. Não é, portanto, de estranhar que, desde a fase preparatória da constituição da associação, se desse uma grande importância à captação de associados, atitude que se manterá até à atualidade.

\footnotetext{
33 O Boletim, 1914, com dados relativos a este ano e ao anterior, p. 112. A publicação, ao longo dos anos, divulgou listas exaustivas dos produtos transacionados, com respectivo valor e quantidade, no circuito entre os portos de Lisboa e do Rio de Janeiro.

${ }^{34}$ As relaçóes estabelecidas entre a Câmara Portuguesa de Comércio e Indústria e os dirigentes portugueses, neste momento, como após 1926, foram analisadas por Paulo (2004).
} 
Como se compunha o quadro social da Câmara Portuguesa de Comércio e Indústria, do Rio de Janeiro? De imediato, poderemos dizer: portugueses, ${ }^{35}$ que se apresentavam, na grande maioria dos casos, com idades compreendidas entre os 26 e os 45 anos (72,5\%). Acompanhando as características do movimento de emigraçáo de Portugal para o Brasil, a que se associava uma menor capacidade de investimento e espírito empreendedor, os mais jovens, entre os 19 e os 25 anos, constituíam o grupo menos representado, no período que decorre entre 1916 e 1930 :

Grupos etários dos sócios da CPCI (1916-1930)

\begin{tabular}{|c|c|}
\hline Grupo de Idade (anos) & Ocorrências \\
\hline I (19-25) & 18 \\
\hline II (26-35) & 234 \\
\hline II (36-45) & 305 \\
\hline IV (46-55) & 135 \\
\hline V (56-65) & 41 \\
\hline Total & 743 \\
\hline
\end{tabular}

Fonte: Livros de Registos de Associados.

Já numa fase mais tardia da vida ativa, a partir dos 46 anos de idade, também os empresários-imigrantes iniciavam um movimento de menor procura, com um claro desinteresse após os 56 anos (1,3\%). A partir de meados da década de 1930, aumentará, consideravelmente, o número de brasileiros que se tornam sócios da CPCI. Mais náo são do que a segunda geraçáo de imigração, nascida já no Brasil.

Sobre a naturalidade dos homens que deixaram Portugal, para se estabelecer, como empresários, na praça do Rio de Janeiro, poderemos dizer que chegaram de todo o país, de norte a sul, sem esquecer os arquipélagos da Madeira e dos Açores, e mesmo as colónias africanas (Angola e Cabo Verde). Lisboa e Porto, como cidades demograficamente distintas do resto do país,

\footnotetext{
${ }^{35}$ Dos 784 sócios que identificaram o país de origem, só um tinha nascido no Brasil, em Obirui. O seu nome, António Fernandes dos Santos, permite-nos pensar numa segunda geração de imigração portuguesa. A disparidade registada nos totais dos valores apresentados decorre da presença/ausência de informação registada pelo novo associado, aquando do preenchimento da ficha de admissão.
} 
que geravam ambientes de empreendedorismo mais contagiantes, cederam os contingentes de emigrantes mais numerosos, como se pode constatar no quadro seguinte:

Naturalidade dos sócios da CPCI (1916-1930)

\begin{tabular}{|l|c|}
\hline Localidade de Origem & Ocorrências \\
\hline Porto & 69 \\
\hline Lisboa & 50 \\
\hline Vila Real & 22 \\
\hline Braga & 21 \\
\hline Oliveira de Azeméis & 16 \\
\hline Chaves & 15 \\
\hline Vila Nova de Gaia & 14 \\
\hline Vila da Feira & 14 \\
\hline Paredes & 12 \\
\hline Guimarães & 12 \\
\hline Vila Nova de Famalicão & 11 \\
\hline S. João da Madeira & 11 \\
\hline
\end{tabular}

Fonte: Livros de Registos de Associados.

Os associados da Câmara Portuguesa de Comércio e Indústria, do Rio de Janeiro, pertenciam, sem dúvida, a um grupo mais restrito de imigrantes, com experiências de vida do mundo urbano, que não correspondiam a algumas características-tipo constantes numa historiografia mais atenta aos grandes movimentos.

Trabalhando dados mais agregados, sobre a origem dos associados da CP$\mathrm{CI}$, poderemos acrescentar que o movimento da emigração se fez sentir, particularmente a partir dos distritos do Norte $(53,6 \%)$, tal como se pode constatar através da lista constituída pelas localidades identificadas como naturalidade pelos associados: 
Origem dos sócios da CPCl, por zonas (1916-1930)

\begin{tabular}{|c|l|c|}
\hline ZONA & \multicolumn{1}{|c|}{ Distritos } & Ocorrências \\
\hline Norte & Porto, Braga, Vila Real, Viana do Castelo, Bragança & 353 \\
\hline Centro & Aveiro, Viseu, Coimbra, Guarda, Leiria, Santarém, Castelo Branco & 211 \\
\hline Sul & Faro, Beja, Évora, Portalegre & 16 \\
\hline
\end{tabular}

Fonte: Livros de Registos de Associados.

Esta perspectiva, organizada à escala dos distritos, mostra que os associados da CPCI, entre 1916 e 1930, acompanhavam as características do movimento da emigração portuguesa, rumo ao Brasil. A população da região a Sul da linha do Tejo não mostrava propensão para procurar novos destinos de vida, com apenas 16 portugueses oriundos desta zona, representando não mais do que $2,6 \%$ dos associados.

A estabilidade familiar era um dos valores a preservar, na procura de uma mais perfeita integração na sociedade de acolhimento. A documentação da CPCI náo permite, obviamente, conhecer o modelo de casamento dos nossos empresários, fixados no Rio de Janeiro. Isto é, desconhecemos se a sua escolha recaía preferencialmente sobre uma "patrícia", que atravessava o Atlântico para concretizar a criaçáo de um lar, ou se ocorria um significativo encantamento pela mulher brasileira. Trabalho recente sobre a participação das comunidades imigrantes na vida económica e social do Rio de Janeiro refere que no início do século XX a relaçáo era de 319 imigrantes portugueses para cada 100 portuguesas que aqui chegavam (Pamplona, 2003:58). Neste primeiro grupo de sócios analisados, 69\% apresentava-se com o estado civil de casados. A sociedade carioca privilegiava o tranquilo evoluir do seu quotidiano e a tendência será a valorização da família, como estrutura de equilíbrio social.

De forma clara, sabemos, através da matrícula de sócios após 1930, que há uma segunda geração de empresários-imigrantes que vai optar pela dupla nacionalidade, em resultado do nascimento já no Brasil, do cruzamento com naturais do país e, não podemos esquecer, da salvaguarda dos interesses empresariais, melhor resguardados na situação de "cidadão nacionalizado brasileiro", como passará a constar nas fichas de inscrição. 


\subsection{Atividades económicas}

Continuamos a mobilizar a informação registada pelos associados, no momento da sua admissão na CPCI do Rio de Janeiro. Nem sempre o fizeram de forma exaustiva, falhando informação fundamental para traçarmos o seu perfil, como imigrante e como agente económico. A leitura do conjunto dos resultados obtidos aponta para grande diversidade de profissóes com que se apresentavam, no momento de solicitarem a sua entrada na associação. Desta diversidade decorriam, sem dúvida, diferentes níveis de capital escolar. Claramente que não estamos perante a presença do imigrante falho de literacia; a que associava algum capital financeiro, que vinha investir num mercado promissor, onde se falava uma mesma língua.

Não constituiu surpresa verificar que o sector comercial dominava o quadro social da associação, atingindo o valor de $73,9 \%$, relativamente ao total dos sócios, como podemos verificar no quadro seguinte:

\begin{tabular}{|l|c|}
\multicolumn{2}{|c|}{ Profissão dos sócios da CPCl (1916-1930) } \\
\begin{tabular}{|l|c|}
\hline \multicolumn{1}{|c|}{ Profissão dos sócios } & Ocorrências \\
\hline Comerciante & 645 \\
\hline Industrial & 73 \\
\hline Administrativo & 48 \\
\hline Por conta de outrem & 29 \\
\hline Diretor/gerente & 27 \\
\hline Liberal & 17 \\
\hline Capitalista & 9 \\
\hline Comerciante/industrial & 9 \\
\hline Agente cultural & 4 \\
\hline Agricultor & 4 \\
\hline Construtor civil & 3 \\
\hline Diplomata & 3 \\
\hline Artífice & 2 \\
\hline Total & 873 \\
\hline
\end{tabular}
\end{tabular}

Fonte: Livros de Registos de Associados.

A esta forte representação de comerciantes contrapunha-se a de $8,4 \%$ dos associados ligados ao sector industrial.

Os estabelecimentos comerciais, na então capital do Estado brasileiro, apresentavam grande diversidade de oferta, desde os mais especializados em livros, 
joias, perfumes, tabaco, tapetes, louças, artigos em couro, chapéus, calçado, camisas, até, exatamente, aos que apresentavam múltipla oferta. Mas estava-se, claramente, num mercado com características urbanas, que tende para a especialização da oferta. Daí a dimensão do comércio especializado, que representava 34\% dos sócios, como se pode verificar:

Grandes áreas sectoriais económicas (1916-1930)

\begin{tabular}{|c|c|}
\hline Grande Área & Ocorrências \\
\hline Comércio Especializado & 321 \\
\hline Agências e Representações & 120 \\
\hline Comércio de Bens Alimentares & 97 \\
\hline Comércio Não Especializado & 64 \\
\hline Comércio a Retalho & 57 \\
\hline Artes e Ofícios & 48 \\
\hline Comércio de Bebidas & 35 \\
\hline Atividades Financeiras & 29 \\
\hline Indústria de Calçado & 23 \\
\hline Indústria de Bens Alimentares & 20 \\
\hline Materiais de Construção & 17 \\
\hline Indústria de Tecidos, Vestuário e Acessórios & 16 \\
\hline Exportação e Importação & 15 \\
\hline Indústria de Móveis e Utensílios & 13 \\
\hline Indústria Metalomecânica & 13 \\
\hline Outros — Indústria & 13 \\
\hline Indústria de Bebidas & 10 \\
\hline Diplomacia & 8 \\
\hline Profissões Liberais & 8 \\
\hline Indústria de Produtos Químicos & 7 \\
\hline Indústria de Materiais de Construção & 6 \\
\hline Transportes e Viagens & 4 \\
\hline Outros - Comércio & 2 \\
\hline Total & 946 \\
\hline
\end{tabular}

Fonte: Livros de Registos de Associados.

Continuava a verificar-se, ainda, o convívio entre as formas de comércio mais inovadoras com as mais tradicionais e arcaicas: quando se verificava a não especialização da oferta, num mesmo espaço conviviam os mais distin- 
tos produtos, sob a máxima negocial de a oferta ser tão diversa quanto a procura.

Destacamos, entre muitos exemplos possíveis, J. Bento Pinto que, em 1917, associava vidros, papéis pintados e uma componente de sapataria, na avenida do Uruguai, em Niterói; ou a Raul Campos \& C C que, no centro do Rio de Janeiro, na rua dos Ourives, oferecia móveis de vime, tapeçarias, calçados e artigos de aperto, 10 anos depois, em 1927. A profissão "comerciante", que identificou um número tão considerável de sócios, cobria, assim, diferentes patamares de intervenção e de posicionamento no mercado.

A possibilidade de qualquer um poder abrir uma loja, desde que possuísse o capital inicial para o investimento, permitia a reprodução de um grupo laboral sem qualificação profissional específica. O sucesso empresarial ficava, quase inteiramente, à mercê do conjunto das qualidades de iniciativa, de vontade e de método de gestáo do comerciante. Em parte, como dizia Francisco Correia, em 1920, a justificação para o êxito, ou para a sua ausência, residia no ter, ou não ter, sorte (Correia, 1920:10).

Beneficiado da facilidade em intervir no mercado exportador português, o negócio desenvolvido através de agências de representaçôes e consignaçôes, ou mais claramente de importação/exportação, foi muito representativo, na composição da CPCI: apresentaram-se 120 “agentes", entre 1916 e 1930, correspondendo a $12,7 \%$ do corpo social. Instalavam-se nos andares superiores dos prédios ocupados, ao nível da rua, com outro tipo de negócio. Tal como ocorreu com os estabelecimentos dedicados ao comércio, também as agências foram instaladas, preferencialmente, no centro do Rio de Janeiro, até para facilitar o relacionamento com os comerciantes.

Do lado de cá, em Portugal, a partir de 1920, e num movimento de adesão que vai ser mais significativo depois de 1930, deparamos com a necessidade em defender atividades de exportaçáo para o Brasil, com a entrada de agentes económicos instalados no país, como associados da Câmara Portuguesa de Comércio e Indústria, do Rio de Janeiro. A área da exportação será a que mais frequentemente irá acionar a figura do "Sócio Correspondente", prevista desde os primeiros Estatutos. Não foram exclusivamente os vinhos que optaram por esta modalidade para estar presente no mercado do Rio de Janeiro: para uma sociedade urbana, em expansão económica, tornava-se igualmente interessante a presença de ourives nacionais, com capacidade para colocarem os seus produtos além-mar. Tratou-se, para o primeiro dos produtos referidos, da Real 
Companhia Vinícola do Norte de Portugal, para iniciar o movimento, e das firmas de ourivesaria Reis Filho, Lda. e de Celestino da Mota Mesquita, ambas de Celorico de Basto, que entram como sócios correspondentes pela máo de um mesmo proponente, já instalado no comércio carioca. $\mathrm{O}$ mesmo se regista, para facilitar a circulação de conservas, fabricadas em Matosinhos, quando a firma Lopes Coelho Dias \& Cệa se associa, também, como correspondente, em 1921. No período em apreço, pode-se concluir que as empresas portuguesas, em face deste baixo número de adesóes, não tinham ainda procurado criar uma representação mais estável num mercado longínquo, mas com grande apetência pelos produtos portugueses. Daí a presença numerosa de "agentes" locais, como já referimos, que estabeleciam a ponte entre os dois lados do Atlântico.

No sentido de alcançar uma perspectiva sobre o conjunto das atividades desenvolvidas pelos sócios da CPCI, e em termos de uma primeira conclusão sobre esta matéria, organizámos os valores por diferentes tipos de Comércio e de Indústria, sintetizado nos quadros seguintes:

Grandes áreas sectoriais económicas

\begin{tabular}{|l|c|}
\hline Grande área - Comércio & Ocorrências \\
\hline Comércio Especializado & 321 \\
\hline Comércio de Bens Alimentares & 97 \\
\hline Comércio Não Especializado & 64 \\
\hline Comércio a Retalho & 57 \\
\hline Comércio de Bebidas & 35 \\
\hline Total (\%) & $574(60,7 \%)$ \\
\hline
\end{tabular}

\begin{tabular}{|l|l|}
\hline Grande área - Indústria & \multicolumn{1}{|c|}{ Ocorrências } \\
\hline Indústria de Calçado & 23 \\
\hline Indústria de Bens Alimentares & 20 \\
\hline Indústria de Tecidos, Vestuário e Acessórios & 16 \\
\hline Indústria de Móveis e Utensílios & 13 \\
\hline Indústria Metalomecânica & 13 \\
\hline Indústria de Bebidas & 10 \\
\hline Indústria de Produtos Químicos & 7 \\
\hline Indústria de Materiais de Construção & 6 \\
\hline Total (\%) & \\
\hline
\end{tabular}

Fonte: Livros de Registos de Associados. 
Assim, encontrámos imigrantes portugueses em todas as áreas da distribuição, ${ }^{36}$ atingindo $60,7 \%$ no conjunto dos sócios que identificaram a atividade desenvolvida, num total de 946 verificaçóes. Constatámos, ainda, uma organização de mercado perfeitamente urbano, onde o comércio especializado detinha uma forte presença, nas ruas do Rio de Janeiro. Sobre a Indústria, diremos que os 108 sócios da CPCI eram portadores de uma tradição, que Eulália Lobo (2001:31-34) refere para algumas das cidades mais importantes do Brasil. A autora identifica a produçáo de bens alimentares e de tecidos como estando maioritariamente em mãos lusas, ainda no período em estudo. Não procuraram a Câmara Portuguesa na dimensão esperada, não tendo ultrapassado os $11,4 \%$ de presença, no conjunto dos associados.

\subsection{Implantação urbana}

Os empresários-imigrantes portugueses, nestes primeiros anos de vida da CPCI, instalaram-se, quase na totalidade, no Centro da cidade. Mantinha-se o princípio da organização do comércio em torno de locais de acesso facilitado às populaçóes, pela tradição, pelas características da malha urbana (plana, densamente ocupada e a irradiar para todas as zonas da cidade). Era ali o coraçáo da vida económica da cidade.

Desconhecemos o valor do espaço comercial numa zona, ainda hoje, densamente povoada por estabelecimentos comerciais, de serviços e de assegurada clientela. As ruas da Carioca, Uruguaiana, Quitanda, Acre, Alfândega, Ourives, Ouvidor, 1ํ de Março constituíam, tal como ainda hoje, um grande centro comercial a céu aberto. A ocupaçáo, que tinha a Avenida Rio Branco como lugar central, apresentava uma rede expressa na representaçáo constante na planta do centro do Rio de Janeiro, no início do século XX:

\footnotetext{
${ }^{36}$ Deparámos com valores assumidos em diferentes áreas, de um e outro sector, para que já havíamos sido alertados pelos trabalhos de Eulália Lobo (2001). Apurámos alguns valores menos coincidentes, mas que devem ser entendidos à luz de um contexto de associativismo.
} 


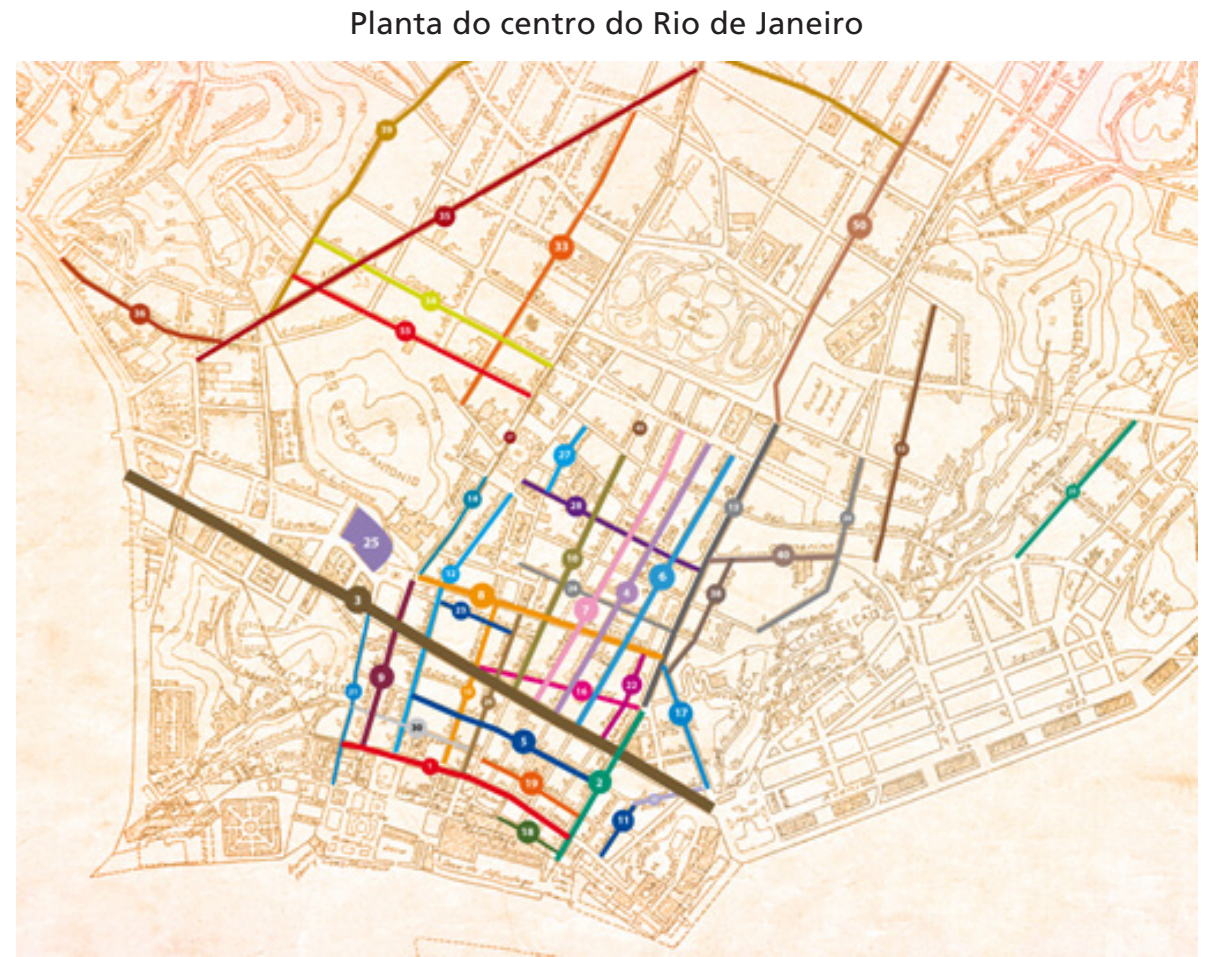

Fonte: Livros de Registos de Associados.

A escolha de outras zonas da cidade, para iniciarem a descentralização, criando outros centros comerciais, foi um movimento que, apesar de pequena dimensão, se apresentou logo nos primeiros anos em que temos o registo de sócios da Câmara (1916). Tal movimento para as periferias não significou uma procura de espaço para uma atividade mais especializada ou para uma diferente forma de intervir no mercado, como começámos por supor. Todas as iniciativas empresariais, apresentadas pelos portugueses que se tornavam sócios da $\mathrm{CPCI}$, apresentavam características similares, em qualquer dos lugares onde surgiam instaladas.

Talvez uma exceção se possa identificar, no que respeita ao bairro da Tijuca. Nesta zona do Rio de Janeiro, contaram-se 12 novas inscriçóes, no período estudado; metade corresponde a empresários ligados ao sector industrial, nomeadamente na área do fabrico de calçado, de que se destaca a Ferreira, Souto $\& \mathrm{C}^{\mathrm{a}}$, presente durante alguns anos nos espaços publicitários do Boletim, que entra para o seu corpo social em 1922. 
$\mathrm{Na}$ sequência deste estudo preliminar, propomo-nos vir a analisar "vizinhanças", decorrentes de potenciais redes de parentesco e de sociabilidade, criadas, estas últimas, sobre a partilha de uma origem geográfica comum ou do desenvolvimento de atividades afins.

\section{Conclusão}

A Câmara Portuguesa de Comércio e Indústria do Rio de Janeiro assumiu-se, verdadeiramente, como uma estrutura representativa de Portugal em território brasileiro. Cuidava da sua imagem perante os seus pares brasileiros, no campo económico, mas também no social.

No debate, sempre atual, sobre a construção identitária da sociedade carioca, coloca-se o lugar do imigrante português. A ótica das abordagens acarreta extremos muito interessantes: desde a perspectiva do seu lugar inquestionável no desenvolvimento da economia e do espaço urbano do Rio de Janeiro, até a criação do português-anedota, que conduz à ideia de atraso, à de pobreza, à de baixos níveis de cultura e de escolaridade. Numa sociedade que carregava o estigma de capital de antiga colónia, não deixariam de existir marcas de repulsa pelo passado. No Rio de Janeiro, esse combate aos valores portugueses foi notório durante as reformas urbanas de Pereira Passos (Abreu, 1988), ocorridas entre 1903 e 1906. Na opinião de Luiz Edmundo, elas teriam sido responsáveis por "transformar em uma cidade moderna e digna a velha cidade portuguesa", declarando "guerra aos bacalhoeiros [...], aos tamanqueiros [...], aos mestres de obras que constroem no estilo compoteira e outros autores do atraso colonial". ${ }^{37}$ Esta era, também, a visão da sociedade onde se instalou a Câmara Portuguesa de Comércio e Indústria. Sem dúvida, que a dignificação dos nossos empresários-imigrantes passou pelo associativismo. Tratava-se de uma comunidade com características distintas, que lhe conferiam, logo à partida, um posicionamento económico notoriamente reconhecido. Pelo acervo fotográfico, aliado às secçóes noticiosas das suas publicações, podemos constatar que foi, também, criando espaços de sociabilidade para uma elite imi-

\footnotetext{
${ }^{37}$ Edmundo (1957). O autor (1878-1961) foi jornalista, poeta e estudioso da história do Rio de Janeiro.
} 
grante, à medida que se impunha numa rede de relaçóes com as instâncias do poder (político, social, cultural). Ser sócio da CPCI significava ter um "ancoradouro", socialmente reconhecido. Podia significar solidariedade e ajuda em tempos difíceis. Podia significar a partilha de um espaço e de uma identidade que prolongava o espaço português no Brasil.

Com os associados da CPCI, conhecemos um sector da imigraçáo portuguesa que obedecia a lógicas algo distintas do que tem sido estudado, em face da posse de um capital inicial, de níveis de escolaridade variável, que lhes proporcionava um lugar de destaque na sociedade de acolhimento. Se em Portugal, quando em visita ou em situação de retorno, era apelidado de "o brasileiro", no Rio de Janeiro, como em outras cidades do Brasil, aspiravam a ser respeitosamente "o português".

Ao concluir, mais do que refletir sobre os resultados alcançados, nesta fase, interessa identificar um conjunto de informaçóes que não foi possível mobilizar e que fomos reconhecendo, ao longo do texto. Sentimos a necessidade de conhecer a realidade empresarial do Rio de Janeiro, em particular, de forma a compreender em pleno a atuação do sócio, como empresário, e da Câmara, enquanto associação de classe. Outro dado importante decorre da informação respeitante a cada empresa ou iniciativa: capital investido, fonte de financiamento, tipo de sociedade, quando existe, dimensão, objeto, participação familiar, organização, "história de vida", capacidade de inovação, estratégias de adequação ao mercado. No âmbito da criação de uma sociabilidade promovida pela associação, também é importante conhecer espaços, mas igualmente estratégias para criar ou manter uma elite, entre a colónia portuguesa.

Finalmente, deverá ser analisada a forma como a Câmara Portuguesa de Comércio e Indústria do Rio de Janeiro se relacionou com o poder, ou melhor, com os poderes. Nomeadamente, a forma como no seu interior se produziu o efeito ideológico das alteraçôes dos regimes políticos, em Portugal e no Brasil, ao longo do século XX.

\section{Fontes (CPCl)}

Livros de Atas da Diretoria (1912-1930)

Fichas de associados (1916, como primeiro ano disponível -1930)

Livros de Diário de Contabilidade (1912-1927) 
Relatório do Conselho Diretor (1912-1924, como último ano disponível)

Boletim Mensal da Câmara Portuguesa de Comércio e Indústria do Rio de Janeiro (n. 1, Jan. 1919/Fev. 1931)

Correspondência avulsa

\section{Referências}

ABREU, Maurício. Evolução urbana do Rio de Janeiro. Rio de Janeiro: Zahar, 1988.

ALVES, Jorge F. O emergir das associaçôes industriais no Porto (meados do século XIX). Análise Social, Lisboa, v. XXXI, n. 136-137, p. 527-544, 1996.

. Os "brasileiros" da emigração no Norte de Portugal. In: (Coord.). Os "brasileiros" da emigração. Famalicão: Câmara M. de Famalicão, 1999. p. 233-247.

BONIFÁCIO, Maria de Fátima. A Associação Comercial do Porto no contexto político-económico nortenho e nacional. Análise Social, Lisboa, v. XXII, n. 91, p. 331-367, 1986.

BRITO, J.M. Brandão de. Associação Industrial Portuense. In: ROSAS, F.; (Dir.). Dicionário de história do Estado Novo. Lisboa: Círculo de Leitores, 1996. v. 1, p. 75-76.

CORREIA, Francisco. O problema comercial. $8^{a}$ Conferência. Diário de Notícias, Rio de Janeiro, 1920. p. 10.

DURKHEIM, Émile. A divisão do trabalho social. Lisboa: Presença, 1989 [1893]. v. 1.

EDMUNDO, Luiz. O Rio de Janeiro do meu tempo. Rio de Janeiro: Imprensa Nacional, 1957.

EVANGELISTA, Helio de Araujo. Rio de Janeiro, uma cidade portuguesa com certeza: uma proposta para manter a característica lusitana da cidade. Rio de Janeiro, E-Papers, 2008.

FREITAS, Sónia Maria. Presença portuguesa em São Paulo. São Paulo: Imprensa Oficial, 2006.

FREITAS FILHO, Almir Pita. A colónia portuguesa na composição empresarial da cidade do Rio de Janeiro no final do século XIX e início do XX. In: LESSA, Carlos (Org.). Os lusiadas na aventura do Rio moderno. Rio de Janeiro: Record, 2002. p. 163-197.

. Instituiçôes, agentes sociais e desenvolvimento económico: Rio de Janeiro, 1890-1945. Estudos do Século XX, "Empresas e Empresários", n. 4, p. 115-137, 2004 . 
GERSON, Brasil. História das ruas do Rio de Janeiro. Rio de Janeiro: Lacerda Editores, 2000.

LESSA, Carlos. Rio, uma cidade portuguesa? In: (Org.). Os lusiadas na aventura do Rio moderno. Rio de Janeiro: Record, 2002. p. 21-61.

LOBO, Eulália. Imigração portuguesa no Brasil. São Paulo: Hucitec, 2001. et al. Cartas de Antônio Dias Leite (1870-1952): um olhar sobre uma época de transformação. Rio de Janeiro: Lidador, 2005.

MARICHAL, Carlos; TOPIK, Steven. O estado e o crescimento económico na América Latina: Brasil e México, 1880-1920. História Econômica \& História de Empresas, São Paulo, v. VI, p. 7-34, 2003.

MARTINHO, Francisco Carlos P. O imigrante português no mundo do trabalho, nos movimentos sociais e nas organizaçóes sociais do Rio. In: LESSA, Carlos (Org.). Os lusiadas na aventura do Rio moderno. Rio de Janeiro: Record, 2002. p. 199-240.

MATOS, Ana Maria C. Sociedades e associaçóes industriais oitocentistas: projetos e açôes de divulgação técnica e incentivos à atividade empresarial. Análise Social, Lisboa, v. XXXI, n. 136-137, 1996.

MENDES, José M. Amado. Evolução da economia portuguesa. In: MATTOSO, J. (Dir.). História de Portugal. Lisboa: Círculo de Leitores, 1993. v. V, p. 315-323.

MENEZES, Wagner Chagas de. Costurando os retalhos: configuração e cotidiano do pequeno comércio de espaço central da cidade do Rio de Janeiro. Tese (doutorado) — Instituto de Ciências Humanas, Universidade Federal Fluminense, 1998.

MOURÃO, Alda. A criação da imagem empresarial através da publicidade. Outros Combates pela História, Coimbra, p. 311-325, 2010.

PAMPLONA, Marco Antonio. Revoltas, repúblicas e cidadania. Rio de Janeiro: Record, 2003.

PAULO, Heloisa. Entre republicanos e conservadores: a Câmara Portuguesa de Comércio e Indústria do Rio de Janeiro. Estudos do Século XX, "Empresas e Empresários", n. 4, p. 369-390, 2004.

PEREIRA, Luiz Carlos B. Empresários, suas origens e as interpretações do Brasil. In: SZMRECSÁNYI, Tamás (Org.) et al. História de empresas e desenvolvimento econômico. São Paulo: Edusp, 1994. p. 143-164.

PIÑERO, Théo. Os negociantes e suas entidades no Império do Brasil. In: MOREIRA, Regina; FONTES, Paulo (Org.). A Casa do Empresário: trajetória da Associação Comercial do Rio de Janeiro. Rio de Janeiro: Associação Comercial RJ/FGV, 2009. p. 73-113.

ROEDEL, Hiran. Comunidade portuguesa na cidade do Rio de Janeiro no final do 
séc. XIX e início do XX. In: LESSA, Carlos (Org.). Os lusíadas na aventura do Rio moderno. Rio de Janeiro: Record, 2002. p. 117-143.

ROSAS, Fernando; ROLLO, Maria Fernanda (Coord.). História da Primeira República portuguesa. Lisboa: Ediçōes Tinta-da-China, 2009.

SERRA, M.V.; RABAÇA, Carlos Alberto (Org). De pai para filho: imigrantes portugueses no Rio de Janeiro. Rio de Janeiro: Documenta Histórica, 2009.

SILVA; Maria Beatriz Nizza da. Documentos para a história da emigração portuguesa no Brasil (1850-1938). Rio de Janeiro: Editorial Nórdica, 1992. 